\title{
Non Destructive Studies On Engineered Cementitious Composites Using Microsilica \& Polypropylene Fibre
}

\author{
K.B SHOBA, P.ASHA
}

\begin{abstract}
This study focuses on assessing the durability property of engineered cementitious composites using Ultrasonic pulse velocity method (direct and semi direct) to compute the compressive strength. Even the effect of mineral admixture on the mortar properties for different curing regimes shall be determined using this method. Mortar specimens containing microsilica in different percentages ranging from $5 \%$ to $25 \%$, replacing portland cement by weight and adding polypropylene fibres ranging from $0.5 \%$ to $2 \%$ are chosen for evaluation. $20 \%$ of microsilica and $2 \%$ of polypropylene fibres induced to increase the range of UPV from $3463 \mathrm{~m} / \mathrm{s}$ to $3505 \mathrm{~m} / \mathrm{s}$ for 7 and 28 day curing regimes and also the compressive strength significantly improved for the above constituent. However there was a marginal decrease in the compressive strength and UPV outcomes when cement is replaced by microsilica greater than $20 \%$. A relationship had been framed between ultrasound pulse velocity and compressive strength.
\end{abstract}

Keywords: Durability, Engineered cementitious composites, Ultrasonic pulse velocity, Microsilica.

\section{INTRODUCTION}

In order to estimate the quality of concrete, Non Destructive Testing methods are widely used. Basically, concrete will be considered as a homogeneous material in this method and eventually this is based on measuring the velocity which seem to be propagating and in turn relates with the elastic modulus and mechanical properties in a closer manner. This can also be utilized to evaluate the hardening and setting systems of cementitious materials. The rheology of concrete, cementitious composites and mortar are highly complex and shall be considered as a composition of porous composite materials, highly complex multiphase material. Thus concrete shall be heterogeneous with composite range of scales making the ultrasonic waves highly irregular in concrete, hindering non destructive testing. The rate at which the ultrasonic pulses travel in a solid depends upon density and elastic property of the material. Stress wave methods for deep foundations and structures, magnetic nuclear methods, electrical methods, permeability and infrared thermograph are some of the non destructive testing methods used for visual inspection. ASTM C 597-97 "Standard test method for pulse velocity through concrete" has been standardized to assess the pulse velocity of mortars along with its effects. In concrete industry, it is essential to use supplementary cementitious materials replacing cement content to curb the global impact.

Revised Manuscript Received on December 22, 2018.

K.B.Shoba, research scholar in Department of Civil Engineering, St.Peter's Institute of Higher Education and Research, Avadi, Chennai.

Dr.P.Asha, working as Professor, Department of Civil Engineering, St.Peter's Institute of Higher Education and Research, Avadi, Chennai.
Microsilica, which is a by-product of silicon metal having 95.7\% of $\mathrm{SiO}_{2}$ and extreme fineness shall consider as effective pozzolanic material. It has multiple advantages where it reduces the permeability of concrete to $\mathrm{Cl}$ ions (Chloride) thus protecting the reinforcement from corrosion and highly adaptive in the areas of high chloride content environment. Using electro-acoustical transducer, elastic waves are generated in the form of pulses transferred in direct contact with the surface of the concrete thereby after traversing, the received pulses are converted to electrical energy using a second transducer.

\section{LITERATURE REVIEW}

K.B.Shoba et al. (July 2018) [1] Study on replacement of cement by micro silica $(20 \%)$ along with $(1.5 \%)$ of polypropylene fiber in ECC Matrix.

Lafhaj (2006) [2]summarized that a significant decrease in velocity shall be observed with the increase in porosity say for complete saturated material if the reduction in velocity is of $15 \%$ then porosity increases from $8 \%$ to $13.5 \%$

Mandandoust et.al (2010) [3] revealed that there are many calibrations influencing factors under ideal conditions which in the sense unlikely to achieve $95 \%$ confident limits of better than $20 \%$ higher or lower in predicting the strength for insitu concrete.

Mohammed et.al (2011) [4] examined the fresh and hardened properties of concrete containing rubbercrete as a replacement of fine aggregate. The UPV values of the rubbercrete decreased with an increase in the percentage of crumb rubber content and decrease with an increase in water-cement ratio. Also he revealed that UPV values tend to elevate when the curing age increases.

Trtnik (2009) [5] exhibited the importance with respect to the factors influencing aggregate. He also said that it cannot be neglected for accurate prediction of compressive strength of concrete through UPV. There are chances for increase in UPV results when aggregate content has increased and decrease in compressive strength however they both rely on mix design.

Ye et.al (2004)[6]concluded that UPV is governed by air/water phase present in the cement paste where air bubbles in the water act as a dominant factor determining UPV in two stages.

Zhang et.al (2009) [7]studied the hydration of oil well cement slurries using UPV and noted three different time lapsing regimes categorizing rapid increase, slow increase and constant and concluded that the patterns are similar in mortar and concrete.

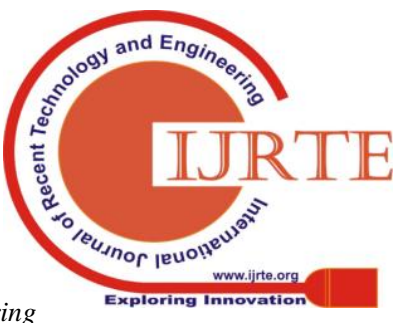


Kheder et.al (1999) [8] found that samples with accelerated curing provide better correlations between strength and density, strength and UPV

Krishna Rao et.al (2010) [9] noted that there was no significant differences between UPV outcomes from concrete samples subjected to membrane curing and conventional water curing.

\section{RESEARCH SIGNIFICANCE}

In this study, the main objective is to investigate the durability properties in terms of nondestructive testing for the proposed ECC specimens. The water-cement ratio is kept constant at 0.3 . The replacement levels of microsilica are 5\%,10\%, 15\%, $20 \% .25 \%$ respectively and the percentage of polypropylene fibres considered are $0.5 \%, 1 \%, 1.5 \%, 2 \%$ respectively.

\section{EXPERIMENTAL PROGRAM}

Ordinary Portland cement of grade 53 confirming to IS 12269-2013 was used in this study. Densified microsilica $(0.76 \mathrm{~g} / \mathrm{cc})$, fine and coarse aggregate were procured from local sources. The chemical analysis and physical properties are presented in Tables 1, 2 and 3 respectively.

Table.1 Physical Properties of OPC 53 grade

\begin{tabular}{|l|l|l|}
\hline S. No & Test Conducted & Results \\
\hline 1 & Fineness & $277 \mathrm{~m}^{2} / \mathrm{kg}$ \\
\hline 2 & Initial setting time & $182 \mathrm{~min}$ \\
\hline 3 & Final setting time & $267 \mathrm{~min}$ \\
\hline 4 & $\begin{array}{l}\text { Soundness by Le- Chatelier } \\
\text { Method }\end{array}$ & $1.2 \mathrm{~mm}$ \\
\hline 5 & Compressive Strength & \\
\hline $5 \mathrm{a}$ & 3 days & $32 \mathrm{MPa}$ \\
\hline $5 \mathrm{~b}$ & 28 days & $53 \mathrm{MPa}$ \\
\hline
\end{tabular}

Table.2 Physical Properties of Microsilica

\begin{tabular}{|c|l|c|}
\hline S. No & Physical Properties & Results \\
\hline 1 & Physical State & Micronized \\
\hline 2 & Odour & Odourless \\
\hline 3 & Appearance & Ash in Color \\
\hline 4 & Packed Density & $0.78 \mathrm{gms} / \mathrm{cc}$ \\
\hline 5 & Specific Gravity & 2.64 \\
\hline 6 & Moisture \& Oil absorption & $0.059 \% \& 56 \mathrm{ml} / 102 \mathrm{gms}$ \\
\hline
\end{tabular}

Table.3 Chemical Analysis of Microsilica

\begin{tabular}{|c|c|c|}
\hline S. No & Chemical Properties & Results \\
\hline 1 & $\mathrm{SiO}_{2}$ & $99.8 \%$ \\
\hline 2 & $\mathrm{Al}_{2} \mathrm{O}_{3}$ & $0.044 \%$ \\
\hline 3 & $\mathrm{Fe}_{2} \mathrm{O}_{3}$ & $0.042 \%$ \\
\hline 4 & $\mathrm{TiO}_{2}$ & $0.002 \%$ \\
\hline 5 & $\mathrm{CaO}, \mathrm{MgO}, \mathrm{K}_{2} \mathrm{O}$ & $0.001 \%, 0 \%, 0.002 \%$ \\
\hline 6 & $\mathrm{Na}_{2} \mathrm{O}, \mathrm{Loss}$ on ignition & $0.003 \%, 0.016 \%$ \\
\hline
\end{tabular}

Concrete mixtures were prepared in different constituents adding $5 \%, 10 \%, 15 \%, 20 \%$ and $35 \%$ by mass to portland cement. For each proportion three samples of $150 \mathrm{~mm}$ cube specimens were prepared and stored in lime saturated water at laboratory temperature. Samples were tested at 7 and 28 days in accordance with ASTM C 597-97. The maximum energy propagates at right angles to the face of the transmitting transducer. The pulse velocity measurements are taken by placing two transducers on either opposite faces and adjacent faces shown in Fig.1

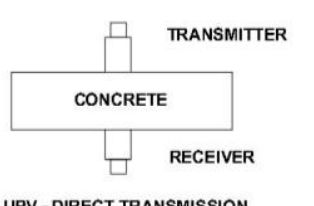

UPV - DIRECT TRANSMISSION

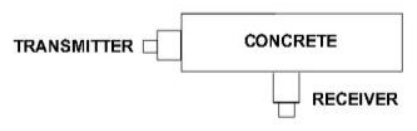

UPV - SEMI DIRECT TRANSMISSION
Fig.1 Propagating and receiving ultrasonic pulses

Apart from two different methods, direct transmission seem to be the most sensitive when compared with indirect transmission as this has to be used when one face of the concrete specimen has access and to find crack or the extent of surface defect. Velocity is calculated from the distance between either of the transmitters and the transit time measured electronically which can be represented as follows $v=l / t$

If large air voids are present in the material then, ultrasonic pulses cannot be transmitted. In case if the voids exists in which the pulse propagates, the instrument indicates the time taken by that particular pulse to circumvent the void via the fastest path.

\section{RESULTS AND DISCUSSIONS}

\subsection{Effect of Microsilica on the compressive strength and UPV}

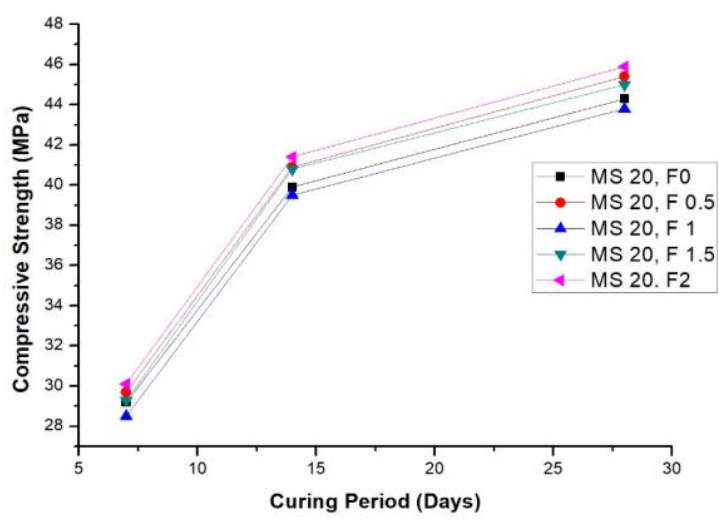

Fig.2 Relationship between compressive strength vs curing regime for Microsilica

Fig,2 represents the increase in compressive strength at 7,14 and 28 days curing regimes of the proposed ECC specimens due to the addition of microsilica and polypropylene fibres and the maximum compressive strength gained when cement is replaced by $20 \%$ of microsilica and $2 \%$ of polypropylene fibres.

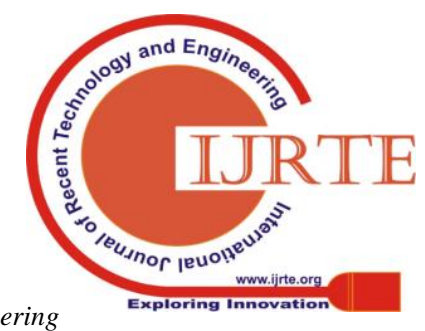


However after $20 \%$ of microsilica replacement, the compressive strength of the ECC specimens decrease with the increase of microsilica content. It was noted that microsilica is more effective in concrete than in mortar due to the bond improvement in aggregate-paste associated with the formation of porous transition phase in lesser manner in microsilica concrete

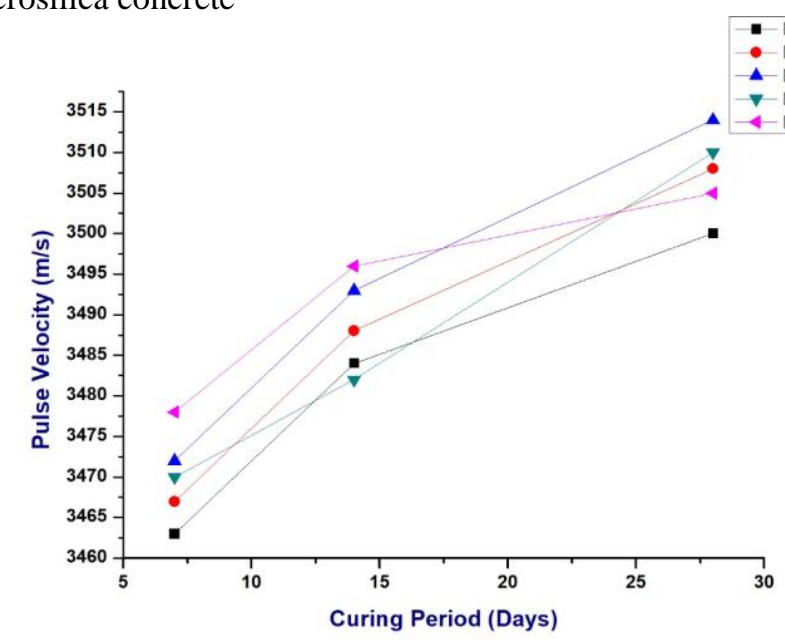

\section{Fig.3 Relationship between UPV $(\mathrm{m} / \mathrm{s})$ vs curing regime} for Microsilica

The effect of mineral admixture on the properties of engineered cementitious composites in different curing regimes shall be determined using UPV. With respect to the outcome, it is noted that UPV decreased with the increase in microsilica content greater than $20 \%$. $10 \%$ of microsilica replacement for portland cement revealed a marginal increase of UPV ranging from $3367 \mathrm{~m} / \mathrm{s}$ to $3750 \mathrm{~m} / \mathrm{s}$ at 7 and 28 day curing regime respectively. Normally the curing regime elevated the UPV for all groups and the rate of increment changed between $8 \%$ and $18 \%$ and even lower when compared with the compressive strength due to curing regime which was exhibited by destructive methodology.

\section{CONCLUSIONS}

Based on the NDT assessment carried out for engineered cementitious composite specimens, the following conclusions were drawn

(1) The compressive strength and UPV were very low for all microsilica groups at early age curing regime say 7 Days.

(2) The maximum compressive strength and UPV was observed for $20 \%$ replacement of microsilica and polypropylene fibre thereby the strength and UPV decreased with the increase in addition content (Microsilica + polypropylene fibre) say $25 \%$.

\section{REFERENCES}

1. K.B.Shoba and P.Asha"Study On Engineered Cementitious Composites Using Micro Silica \& Polypropylene Fibre", International Journal of Civil Engineering and Technology (IJCIET), Volume 9, Issue 7, (July 2018)

2. Lafhaj Z., Goueygou M., Djerbi A., Kaczmarek M. (2006). Correlation between porosity,permeability and ultrasonic parameters of mortar with variable water/cement ratio and water content. Cement and Concrete Research, Vol. 36, pp. $625-633$.

3. Madandoust R., Ghavidel R., Nariman-zadeh N. (2010). Evolutionary design of generalized GMDH-type neural network for prediction of

concrete compressive strength using UPV. Computational Materials Science, Vol. 49, pp. 556-567.

4. Mohammed B.S., Azmi N.J., Abdullahi M. (2011). Evaluation of rubbercrete based on ultrasonic pulse velocity and rebound hammer tests. Construction and Building

Materials, Vol. 25, pp. 1388-1397.

5. Trtnik G., Kavcic F., Turk G., (2009). Prediction of concrete strength using ultrasonic pulse velocity and artificial neural networks Ultrasonics Vol. 49, pp. 53-60.

S 20, 6. Ye, G., van Breugel, K., Fraaij, A.L.A. (2001). Experimental study on ultrasonic pulse velocity evaluation of the microstructure of cementitious material at early age. Heron, Vol. 46, No. 3, pp. 161-167

7. Zhang, J., Qin, L., Li, Z. (2009). Hydration monitoring of cement-based materials with resistivity and ultrasonic methods. Materials and Structures, Vol. 42, pp. 15-24.

8. Zhang, J., Qin, L., Li, Z. (2009). Hydration monitoring of cement-based materials with resistivity and ultrasonic methods. Materials and Structures, Vol. 42, pp. 15-24.

9. Kheder G.F. (1999). A two stage procedure for assessment of in situ concrete strength using combined non-destructive testing. Materials and Structures, Vol. 32, pp. 410-417.

10. Krishna Rao, M.V., Rathish Kumar, P., Khan, A.M. (2010). A sudy on the influence of curing on the strength of a standard grade concrete mix. Facta Universitatis (Series Architecture and Civil Engineering), Vol. 8, No. 1, pp. 23-34.

11. Trtnik G., Turk G., Kavèiè F., Bosiljkov V. B. (2008). Possibilities of using the ultrasonic wave transmission method to estimate initial setting time of cement paste. Cement and Concrete Research, Vol. 38, pp. 1336-1342.

12. Krautkramer $\mathbf{J}$ and Krautkramer $\mathrm{H}$, in Ultrasonic testing of materials (Springer, Berlin), (1990), pp 522-524

13. Rajesh, M., and J. M. Gnanasekar. "Path Observation Based Physical Routing Protocol for Wireless Ad Hoc Networks." Wireless Personal Communications 97.1 (2017): 1267-1289.

14. N. Nithiyanandam, K. Venkatesh, M. Rajesh, Transfer The Levels Of The Monitored Carbon, Nitrogen Gases From The Industries, International Journal of Recent Technology and Engineering, Volume-7 Issue-6S3 April, 2019.

15. Sivanesh Kumar, A., Brittoraj, S., Rajesh, M., Implementation of RFID with internet of things, Journal of Recent Technology and Engineering, Volume-7 Issue-6S3 April, 2019.

16. Rajesh, M., Sairam, R., Big data and health care system using mlearningJournal of Recent Technology and Engineering, Volume-7 Issue-6S3 April, 2019.

\section{AUTHOR'S PROFILE}

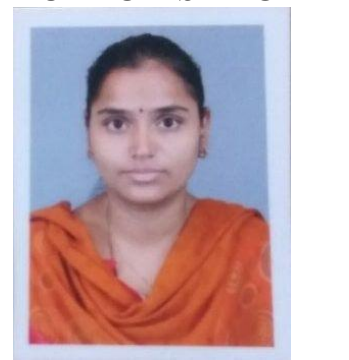

K.B.Shoba is a research scholar in Department of Civil Engineering, St.Peter's Institute of Higher Education and Research, Avadi, Chennai.Completed B.E in Arulmigu Meenakshi Amman College of Engineering,Kanchipuram and M.E in St.Peters university,Avadi. Published a paper on "Study On Engineered Cementitious Composites Using Micro Silica \& Polypropylene Fibre", International Journal of Civil Engineering and Technology (IJCIET), Volume 9, Issue 7, (July 2018). And also with 5 National conferences and 4 international conferences.

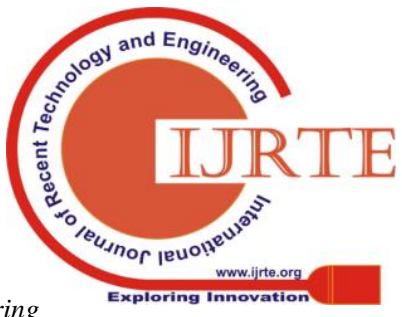




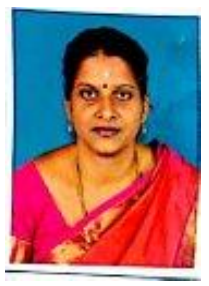

Dr.P.Asha is working as Professor, Department of Civil Engineering, St.Peter's Institute of Higher Education and Research, Avadi, Chennai. Dr.P.Asha completed her B.Tech and M.Tech from Pondicherry Engineering College, Puducherry. Her doctoral work is on Seismic Behaviour of Beam-Column joints and received her Ph.D. from Anna University, Chennai. She has 17 years of experience in academics and industry. She has 18 publications in national and international journals. Her research interests include seismic resistant structures, cementitious composites, sustainable construction etc. She is a recipient of Viswakarma Award. She is a member of ICI, IEI, ISTE and ISSE. 